\title{
A Case Report on Aspergillus lentulus Pneumonia
}

\author{
Şaban Gürcan'1, Melek Tikveşli', Sedat Üstündağ², Beyza Ener ${ }^{3}$ \\ ${ }^{1}$ Department of Medical Microbiology, Trakya University Faculty of Medicine, Edirne, Turkey \\ ${ }^{2}$ Department of Nephrology, Trakya University Faculty of Medicine, Edirne, Turkey \\ ${ }^{3}$ Department of Medical Microbiology, Uludağ University Faculty of Medicine, Bursa, Turkey
}

\begin{abstract}
Background: Aspergillus lentulus was described as a new species in 2005 but it was isolated from Turkey for the first time.

Case report: $A$. lentulus was isolated as the cause of pneumonia from a patient who had renal transplantation 4 months ago. The patient received immunosuppressive treatment after transplantation. A. lentulus was isolated from his sputum as an agent in pneumonia developed 4 months after the transplantation. Leukocytes, blastospores, and hyphae were seen in both Gram- and Giemsa-stained smears of the sputum. The isolate was identified by using the Maren A. Klich algorithm and molecular methods and confirmed by the reference laboratory of the CBS Fungal Biodiversity Centre (The Netherlands). In the susceptibility tests of the isolate, minimal inhibitory concentrations for amphotericin $B$, voriconazole, posaconazole, and caspofungin were found to be $0.5 \mu \mathrm{g} / \mathrm{mL}, 0.25 \mu \mathrm{g} / \mathrm{mL}, 0.125 \mu \mathrm{g} / \mathrm{mL}$, and $0.25 \mu \mathrm{g} / \mathrm{mL}$, respectively. The patient recovered with voriconazole treatment ( $2 \times 200 \mathrm{mg} / \mathrm{day}$ ).
\end{abstract}

Conclusion: The use of the molecular tests is important for identification of $A$. lentulus strains because they are very easily confused with $A$.fumigatus strains according to phenotypic characteristics.

Key Words: Invasive pulmonary aspergillosis, immunocompromised host, Aspergillus lentulus

Received: 17.01.2013 Accepted: 02.08.2013

\section{Introduction}

Aspergillus fungi are widely distributed all over the world in soil and decayed materials (1). At the same time, these Aspergillus species are the most common agents of invasive infections caused by mould in the world (2). They are in second place after Candida spp. when considering all invasive fungal infections (3).

Invasive aspergillosis is usually seen in an immunocompromised host and is an illness related to haematological malignancy, bone marrow/solid organ transplantation, or corticosteroid therapy $(4,5)$. Today, as the mentioned risk factors increase, the incidence of this disease increases at the same rate (5). The most common cause of invasive aspergillosis is Aspergillus fumigatus $(6,7)$. Other causative agents are Aspergillus terreus, Aspergillus niger, Aspergillus flavus, and other species belonging to section Fumigati (5). Recently, A. lentulus has also been reported as a cause of invasive aspergillosis $(6,8,9)$.

A. lentulus was described by Balajee et al. (9) as a new species in 2005. Firstly, a variant of the weak sporulated $A$. fumigatus was isolated from patients with haematopoietic stem cell transplantation as the agent of invasive infection. These strains were found to be different from other species according to characteristics of the phylogenetic origins as well as their different antifungal sensitivities, and they were named as A. lentulus (9). In this paper, the characteristics of the first isolate of $A$. lentulus in Turkey are presented.

\section{Case Report}

The case was a 36-year-old male with chronic renal failure who had been having continuous ambulatory peritoneal dialysis for 8 years. Cadaveric renal tissue was transplanted to the patient approximately 4 months ago. Anti-thymocyte globulin and corticosteroid were initially administered to the patient for immunosuppressive treatment after transplantation. Later, the patient's therapy was continued with tacrolimus, mycophenolate mofetil, and low-dose corticosteroid. The case was admitted by the Trakya University Hospital in treatment of a cough complaint. He had auscultation sign and radiological infiltration in the right lung. In laboratory investigation, his leucocyte count was $6000 / \mu \mathrm{L}$ in haemogram, ESR was $74 \mathrm{~mm} /$ hour, and CRP was $8.44 \mathrm{mg} / \mathrm{dL}$. Leukocytes, blastospores, and hyphae were seen in both Gram- and Giemsastained smears of his sputum. $A$. lentulus was isolated from his sputum as a causative agent of pneumonia that developed 4 months after the renal transplantation. It was again isolated in the second sputum and bronchoalveolar lavage samples. Invasive pulmonary aspergillosis was diagnosed according to clinical, radiological, and microbiological findings in this immunosuppressed host.

The strain was identified by using the Maren A. Klich algorithm and molecular methods. It was incubated for 7 days after inoculation of Czapek Agar $\left(25^{\circ} \mathrm{C}\right), 20 \%$ sucrose Czapek Yeast Agar $\left(25^{\circ} \mathrm{C}\right)$, malt extract agar $\left(25^{\circ} \mathrm{C}\right)$, and Czapek Yeast Agar $\left(25-37^{\circ} \mathrm{C}\right)$. The diameter of Aspergillus colonies were 32 $\mathrm{mm}, 35 \mathrm{~mm}, 36 \mathrm{~mm}$, and $41-47 \mathrm{~mm}$, respectively (Figure 1). 
Table 1. Characteristics of some cases with colonisation or infection caused by Aspergillus lentulus in the literature

\begin{tabular}{|c|c|c|c|c|}
\hline Underlying disease & $\begin{array}{l}\text { Infection/ } \\
\text { Colonisation }\end{array}$ & $\begin{array}{l}\text { Immunosuppressive } \\
\text { therapy history }\end{array}$ & Isolation sample & Reference \\
\hline $\begin{array}{l}\text { Chronic obstructive pulmonary } \\
\text { disease (COPD) }\end{array}$ & Exacerbation of COPD & Yes & Bronchial aspirate & Alhambra et al. (3) \\
\hline $\begin{array}{l}4 \text { haematopoietic stem cell } \\
\text { transplant recipients }\end{array}$ & Invasive aspergillosis & No data & Not data & Balajee et al. (9) \\
\hline $\begin{array}{l}\text { Arterial hypertension and } \\
\text { end-stage chronic kidney } \\
\text { disease }\end{array}$ & Pneumonia & Yes & $\begin{array}{l}\text { Bronchoalveolar } \\
\text { lavage fluid } \\
\text { (BAL) }\end{array}$ & Montenegro et al. (8) \\
\hline Cystic fibrosis & $\begin{array}{l}\text { Colonisation of the } \\
\text { airways }\end{array}$ & No & Sputum & Symoens et al. (13) \\
\hline $\begin{array}{l}\text { Heart transplantation for } \\
\text { ischaemic cardiomyopathy }\end{array}$ & Pneumonia & Yes & $\begin{array}{l}1 \mathrm{BAL}, 1 \text { sputum, } \\
\text { and } 2 \text { tracheal } \\
\text { bronchial secretions }\end{array}$ & Zbinden et al. (14) \\
\hline Renal transplant recipient & Pneumonia & Yes & Sputum & The present study \\
\hline
\end{tabular}

The appearance of the colony was downy to powdery in texture and greenish to white in colour. The reverse colour was cream. Branched conidiophore structures were observed in direct microscopic analysis of the strain prepared with Saboraud Dextrose Agar. Biseriate phialides arising from the round vesicles were also observed (Figure 2). The identification of the $A$. lentulus strain was confirmed with molecular methods by the reference laboratory of the CBS Fungal Biodiversity Centre (The Netherlands). Its susceptibility was tested by the broth dilution method (10). In the susceptibility tests of the strain, minimal inhibitory concentrations (MICs) for amphotericin $\mathrm{B}$, voriconazole, posaconazole, and caspofungin were found to be $0.5 \mu \mathrm{g} / \mathrm{mL}, 0.25 \mu \mathrm{g} / \mathrm{mL}, 0.125 \mu \mathrm{g} / \mathrm{mL}$, and 0.25 $\mu \mathrm{g} / \mathrm{mL}$, respectively. The patient recovered with voriconazole treatment (2x200 mg/day).

\section{Discussion}

Fungal spores of Aspergillus or the other saprophytes in the air may reach the respiratory system and can easily cause infections in an immunocompromised host (1). According to the order of frequency, $A$. fumigatus, $A$. flavus, and $A$. niger were recently isolated as agents of invasive aspergillosis in our hospital (11). Isolations of $A$. lentulus defined in 2005 as a kind of new Aspergillus species were reported in America, Japan, South Korea, Australia, and Spain $(9,12)$. The characteristics of some cases with colonisation or infection caused by $A$. lentulus in the literature are shown in Table $1(3,8,9,13$, 14). However, an isolation of or infection caused by $A$. lentulus was not reported in Turkey until today.

Recently, some fungi in section Fumigati have often been misdiagnosed as A. fumigatus. Today, the use of molecular methods is recommended to prevent false identification of the species in the $A$. fumigatus complex $(2,6)$. The strain isolated in the present study resembled $A$. fumigatus according to many features but its branched conidiophore on microscopic examination attracted attention; therefore, it was thought to be of a different kind. The strain was identified as A. lentulus by the reference laboratory to which it was sent for confirmation by molecular methods.

Although the strains of $A$. fumigatus are intrinsically sensitive to itraconazole, voriconazole, posaconazole, and amphotericin $B, A$. lentulus strains usually have higher $\mathrm{MIC}$ values for these drugs and caspofungin $(6,7,15)$. Average MIC values of eight $A$. fumigatus strains, agents of invasive aspergillosis in our hospital, were $2 \mu \mathrm{g} / \mathrm{mL}, 0.25 \mu \mathrm{g} / \mathrm{mL}, 0.064 \mu \mathrm{g} / \mathrm{mL}$, and $0.064 \mu \mathrm{g} / \mathrm{mL}$ for amphotericin $\mathrm{B}$, voriconazole, posaconazole, and caspofungin, respectively (16). The $A$. lentulus strain in the present study had a fourfold lower MIC for amphotericin B, similar MIC for voriconazole, twofold higher MIC for posaconazole, and fourfold higher MIC for caspofungin in comparison with the $A$. fumigatus strains. As pointed out by Staab et al. (17), A. lentulus may show in vitro low and variable susceptibility for amphotericin $B$, itraconazole, voriconazole, and echinocandins. It is interesting that the susceptibility characteristics of the present strain are slightly different to that antifungal susceptibility reported in the literature. It is also interesting that two out of $14 \mathrm{~A}$. lentulus strains are susceptible to itraconazole in the literature (5). Although these susceptibility tests were repeated eight times, the results were not uniform. Thus, modifications in evaluation of the susceptibility tests to solve different susceptibility results were recommended by the authors (5). In the present study, the susceptibility tests were repeated twice and similar results were obtained. It was evaluated positive in terms of its compliance susceptibility tests due to a good clinical response to voriconazole therapy of the patient.

The different sensitivity characteristics of $A$. lentulus strains compared with $A$. fumigatus strains should be considered in the choice of empirical treatment. The first condition of suitable empirical antifungal therapy is also correct identification of the agent. The use of molecular tests is important for identification of $A$. lentulus strains because they are very easily confused with $A$. fumigatus strains according to phenotypic characteristics. 


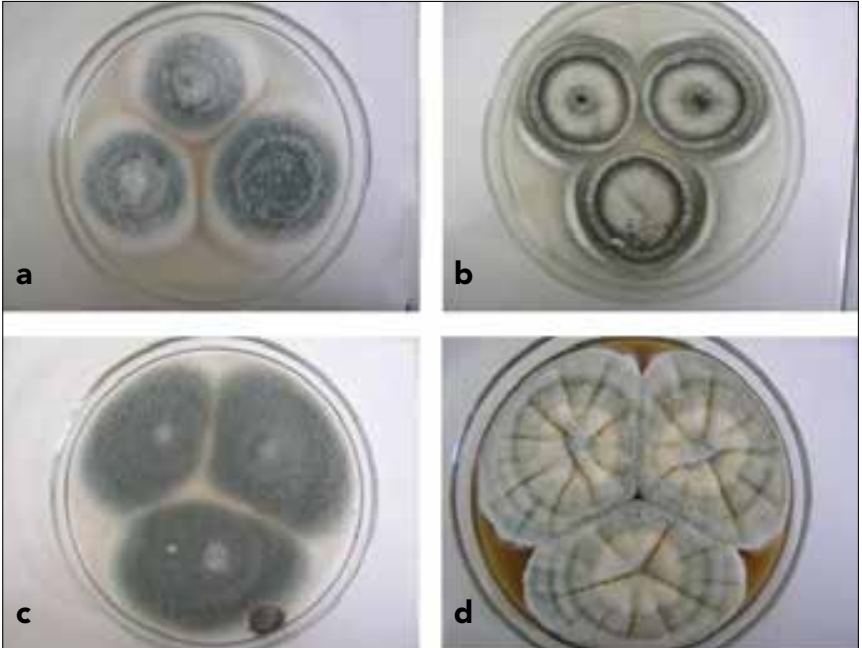

Figure 1. a-d. Colony appearance in Czapek Agar $\left(37^{\circ} \mathrm{C}\right)$ (a), Czapek Yeast Agar (37 $\mathrm{C}$ ) (b), 20\% sucrose Czapek Yeast Agar $\left(25^{\circ} \mathrm{C}\right)(\mathrm{c})$, malt extract agar $\left(25^{\circ} \mathrm{C}\right)(\mathrm{d})$
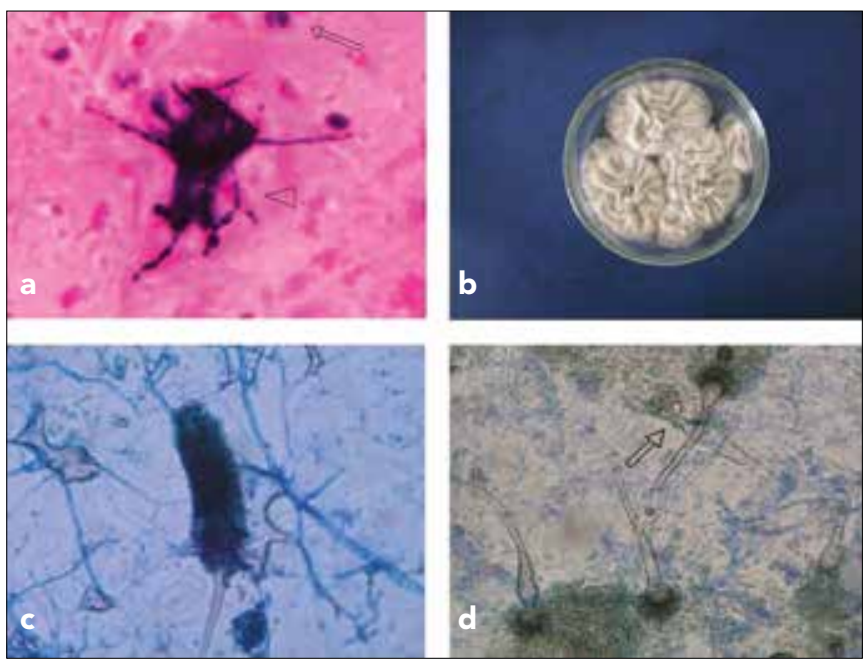

Figure 2. a-d. Leucocytes (arrow) and hyphae (arrowhead) in direct microscopic analysis of sputum (Gram staining) (a), colony appearance in Saboraud Dextrose Agar (SDA; $42^{\circ} \mathrm{C}, 3$ days) (b), conidiospore structure of the strain in slide culture (SDA, $25^{\circ} \mathrm{C}$ ) (c), and microscopic appearance of the branched conidiophores (arrow) in SDA $\left(25^{\circ} \mathrm{C}\right)(\mathrm{d})$

Informed Consent: Written informed consent was obtained from patients. Peer-review: Externally peer-reviewed.

Author contributions: Concept - Ş.G., M.T., S.Ü.; Design - Ş.G., M.T., S.Ü., B.E.; Supervision - Ş.G., M.T., S.Ü.; Design - Ş.G., M.T., S.Ü., B.E.; Resource - Ş.G., M.T., S.Ü. ; Materials - Ş.G., M.T., S.Ü.; Data Collection\&/or Processing - Ş.G., M.T.; Analysis\&/or Interpretation - Ş.G., M.T., B.E.; Literature Search - Ş.G., M.T.; Writing - Ş.G.; Critical Reviews - S.G., B.E.

Acknowledgements: The authors would like to thank Robert $A$. Samson and Neriman Yilmaz (CBS Fungal Biodiversity Centre, The Netherlands) for contributing to the molecular identification process of the strain

Conflict of Interest: No conflict of interest was declared by the authors.

Financial Disclosure: The authors declared that this study received no financial support.

\section{References}

1. Mortensen KL, Mellado E, Lass-Flörl C, Rodriguez-Tudela JL, Johansen HK, Arendrup MC. Environmental study of azole-resistant Aspergillus fumigatus and other aspergilli in Austria, Denmark, and Spain. Antimicrob Agents Chemother 2010;54:4545-9. [CrossRef]

2. Serrano R, Gusmão L, Amorim A, Araujo R. Rapid identification of Aspergillus fumigatus within the section Fumigati. BMC Microbiol 2011;11:82. [CrossRef]

3. Alhambra A, Catalán M, Moragues MD, Brena S, Pontón J, Montejo JC, et al. Isolation of Aspergillus lentulus in Spain from a critically ill patient with chronic obstructive pulmonary disease. Rev Iberoam Micol 2008;25:246-9. [CrossRef]

4. Mortensen KL, Johansen HK, Fuursted K, Knudsen JD, GahrnHansen $B$, Jensen $\mathrm{RH}$, et al. A prospective survey of Aspergillus spp. in respiratory tract samples:prevalence, clinical impact and antifungal susceptibility. Eur J Clin Microbiol Infect Dis 2011;30:1355-63. [CrossRef]

5. Alcazar-Fuoli L, Mellado E, Alastruey-lzquierdo A, Cuenca-Estrella M, Rodriguez-Tudela JL. Aspergillus section Fumigati: antifungal susceptibility patterns and sequence-based identification. Antimicrob Agents Chemother 2008;52:1244-51. [CrossRef]

6. Mellado E, Alcazar-Fuoli L, Cuenca-Estrella M, Rodriguez-Tudela JL. Role of Aspergillus lentulus 14- $\alpha$ sterol demethylase (Cyp51A) in azole drug susceptibility. Antimicrob Agents Chemother 2011;55:5459-68. [CrossRef]

7. Alcazar-Fuoli L, Cuesta I, Rodriguez-Tudela JL, Cuenca-Estrella M, Sanglard D, Mellado E. Three-dimensional models of $14 \alpha$-sterol demethylase (Cyp51A) from Aspergillus lentulus and Aspergillus fumigatus: an insight into differences in voriconazole interaction. Int J Antimicrob Agents 2011;38:426-34. [CrossRef]

8. Montenegro G, Sánchez Puch S, Jewtuchowicz VM, Pinoni MV, Relloso S, Temporitti E, et al. Phenotypic and genotypic characterization of Aspergillus lentulus and Aspergillus fumigatus isolates in a patient with probable invasive aspergillosis. J Med Microbiol 2009;58:391-5. [CrossRef]

9. Balajee SA, Gribskov JL, Hanley E, Nickle D, Marr KA. Aspergillus lentulus sp. nov., a new sibling species of $A$. fumigatus. Eukaryot Cell 2005;4:625-32. [CrossRef]

10. Clinical Laboratory Standard Institute. Reference method for broth dilution antifungal susceptibility testing of filamentous fungi; approved standard. M38-A. PA: Wayne; 2002.

11. Gürcan $S$, Demir M, Altiay G, Tikveşli $M$, Kiliç $H$, Otkun M. Aspergillus spp. isolations from respiratory tract samples in Trakya University Hospital. Tuberk Toraks 2007;55:160-6.

12. Balajee SA, Kano R, Baddley JW, Moser SA, Marr KA, Alexander $\mathrm{BD}$, et al. Molecular identification of Aspergillus species collected for the Transplant-Associated Infection Surveillance Network. J Clin Microbiol 2009;47:3138-41. [CrossRef]

13. Symoens F, Haase G, Pihet M, Carrere J, Beguin H, Degand N, et al. Unusual Aspergillus species in patients with cystic fibrosis. Med Mycol 2010;48:S10-6. [CrossRef]

14. Zbinden A, Imhof A, Wilhelm MJ, Ruschitzka F, Wild P, Bloemberg $G$, et al. Fatal outcome after heart transplantation caused by Aspergillus lentulus. Transpl Infect Dis 2012;14:E60-3. [CrossRef]

15. Staab JF, Kahn JN, Marr KA. Differential Aspergillus lentulus echinocandin susceptibilities are Fksp independent. Antimicrob Agents Chemother 2010;54:4992-8. [CrossRef]

16. Gürcan Ş, Tikveşli M, Eryıldız C, Evci C, Ener B. Antifungal susceptibilities of Aspergillus spp. strains isolated from invasive aspergillosis cases. Mikrobiyol Bul 2010;44:273-8.

17. Staab JF, Balajee SA, Marr KA. Aspergillus section Fumigati typing by PCR-restriction fragment polymorphism. J Clin Microbiol 2009;47:2079-83. [CrossRef] 